\title{
Características do clima urbano em São Carlos/SP a partir de dados de temperatura e umidade relativa do ar e técnicas de sensoriamento (dos alvos)
}

\author{
Camila Riboli Rampazzo ${ }^{(a)}$, João Lima Sant'Anna Neto ${ }^{(b)}$ \\ (a) Departamento de Geografia/Faculdade de Ciências e Tecnologia, Universidade Estadual Paulista "Júlio de \\ Mesquita Filho", camila.rampazzo@hotmail.com \\ (b) Departamento de Geografia/Faculdade de Ciências e Tecnologia, Universidade Estadual Paulista "Júlio de \\ Mesquita Filho", joaolima@ fct.unesp.br
}

Eixo: 3. Climatologia em diferentes níveis escalares: mudanças e variabilidades

\begin{abstract}
Resumo
O processo de urbanização das cidades intensificou as condições de degradação do ambiente e, o clima urbano a partir das ilhas de calor é um dos principais produtos que afeta a qualidade de vida da população. Assim, o presente artigo objetivou a análise das características do clima urbano em São Carlos/SP a partir de dados de temperatura e umidade relativa do ar e técnicas de sensoriamento remoto. Para isso, realizaram-se análises das diferenças termohigrométricas em 8 pontos urbanos no período entre 28 de março a 01 de maio de 2014 às $18 \mathrm{~h}$ (outono) e, verificação da temperatura de superfície dos alvos no dia 04 de abril de 2014. Neste mesmo dia às $18 \mathrm{~h}$ foi realizado transecto móvel nos trajetos A-B e C-D. Foram identificadas diferenças térmicas de até $5,5^{\circ} \mathrm{C}$ e correlação entre as áreas de ocorrência de bolsões de ar e resposta térmica dos alvos em distintos padrões geoambientais.
\end{abstract}

Palavras chave: clima urbano, produção do espaço urbano, diferenças térmicas e higrométricas, sensoriamento remoto, características geoambientais.

\section{Introdução}

O intenso processo de urbanização resultado das transformações desde a Revolução Industrial no século XVIII significaram mudanças significativas para as cidades notadamente pelo uso da técnica e intervenções mais incisivas da sociedade moderna nos ambientes urbanos (DÉAK, SCHIFFER, 1999). Este novo cenário culminou em alterações na paisagem principalmente pela retirada massiva da vegetação arbórea e sua substituição por uma infinidade de usos e ocupação da terra, além da cidade se tornar o centro de fornecimento de serviços e de comércio (AMORIM, 2000).

Segundo dados do IBGE Censo 2010 (Instituto Brasileiro de Geografia e Estatística) o total da população brasileira residindo em áreas urbanas é de $84,36 \%$, valores alcançados pelo intenso fluxo de pessoas oriundas do campo para as cidades a partir dos anos 1970 constituindo arranjos urbanos desprovidos de planejamento e infraestrutura adequada, segundo Monteiro (2009, p.10) "onde o improviso (ilegal) superava, de muito, o planejado (legal)". 
Assim, as cidades passam se tornam os locais de maior intervenção e modificação por meio da ação do homem constituindo espaços produzidos que agregam novos elementos como, desmatamento, asfaltos, construções, entre outros, que remete a não existência de espaços inalterados pela ação humana (BARBIRATO, SOUZA, TORRES, 2007; LOMBARDO, 1985; MONTEIRO, 2009).

A superfície natural torna-se predominantemente impermeabilizada devido à concentração de áreas construídas com materiais construtivos inadequados que dificultam a infiltração da água e aumenta o armazenamento de calor, situação que é prejudicada pela ausência de vegetação arbórea e, associados, tais processos alteram o balanço de energia e acabam por gerar um clima urbano particular da cidade (AMORIM, 2011, p.134).

Monteiro (1990, p.10) considera que "o clima urbano nasceu da comparação com o contraste oferecido com o campo circundante evidenciando o caráter fundamental da cidade como espaço localizado de contínua, cumulativa e acentuada derivação antrópica do ambiente”. Conforme acentua Lombardo (1985):

Com a expansão das cidades, modifica-se substancialmente a paisagem natural. A grande concentração de áreas construídas, parques industriais, adensamento populacional, pavimentação asfáltica, associados à concentração de poluentes, criam condições para alterar o comportamento da baixa troposfera (camada limite), e em ambientes urbanos (LOMBARDO, 1985, p.23).

Deste modo, sendo o clima urbano o produto das alterações que o homem provoca no ambiente natural e, considerando que é o próprio homem que habita esse meio modificado/alterado, por consequência sabe-se que é a própria população citadina a maior prejudicada pelas influências das alterações climáticas na escala local intraurbana. Nota-se então que no contexto da modernidade as cidades possuem uma gama de possibilidades designada por Sant'Anna Neto (2011, p.46) como polissêmica na medida em que “[...] exige uma ressignificação do conceito de ambiente urbano. [...] como espaços produzidos, ao mesmo tempo em que criam oportunidades civilizatórias, também se transformam em armadilha ambiental".

Em relação às alterações do clima local nas cidades tem-se na configuração de ondas de calor, chuvas intensas, aumento da amplitude térmica, formação de ilhas de calor, como alguns dos principais insumos de configurações climáticas que afetam a qualidade de vida dos grupos sociais nos ambientes urbanos.

Tendo o aumento da temperatura como inerente aos ambientes urbanos, a presente proposta tem por objetivo analisar as características do clima urbano em São Carlos/SP (Figura 1) a partir de dados in situ de temperatura e umidade relativa do ar e, técnicas de sensoriamento (dos alvos). Para isso, serão consideradas as características geoambientais e urbanas dos distintos setores geográficos na definição das 
maiores e menores diferenças térmicas. Em relação à definição destas características em estudos climáticos, segundo Fialho (2012):

O conhecimento das feições topográficas do sítio é de extrema importância [...] porque, em pequenas distâncias dentro da própria estrutura interna das cidades, existem significativas diferenças de microclima, oriundas da morfologia da superfície e da presença ou não de vegetação. Tais fatores geram alterações do comportamento térmico que comprometem a qualidade de vida e o conforto térmico das cidades (FIALHO, 2012, p.85).

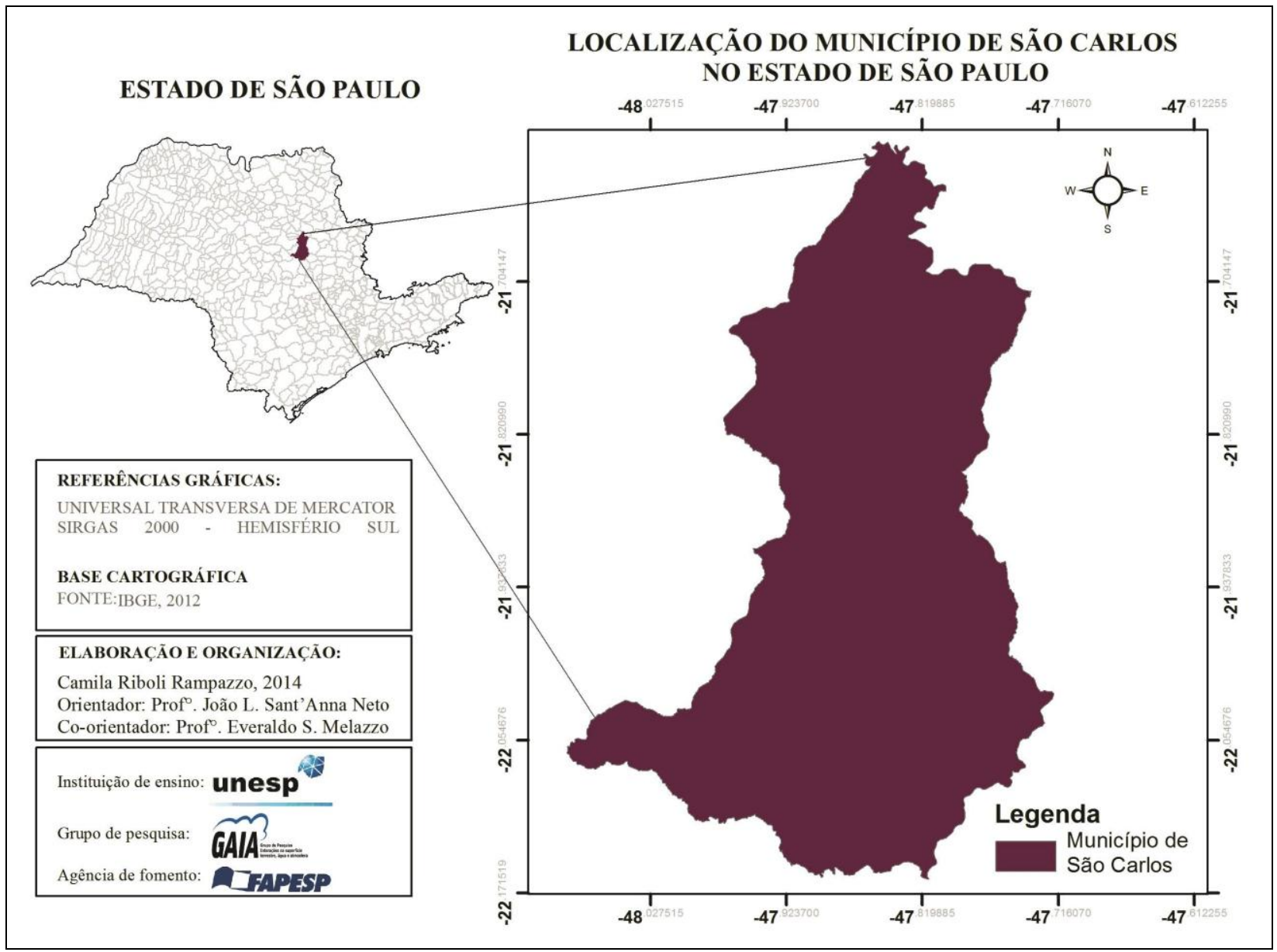

Figura 1 - Mapa de localização do município de São Carlos no Estado de São Paulo, Brasil

Sob esta perspectiva, considerando os aspectos que influenciam nas respostas térmicas do ambiente, Labaki et al (2011, p.26) consideram que:

Em relação ao ambiente construído, na composição das superfícies da base e definidoras do espaço, importam as características térmicas dos materiais, a capacidade de absorção de radiação solar e emissão de onda longa, os ganhos e perdas de calor definidos por suas características quanto à rugosidade e permeabilidade. Importam ainda a disposição 


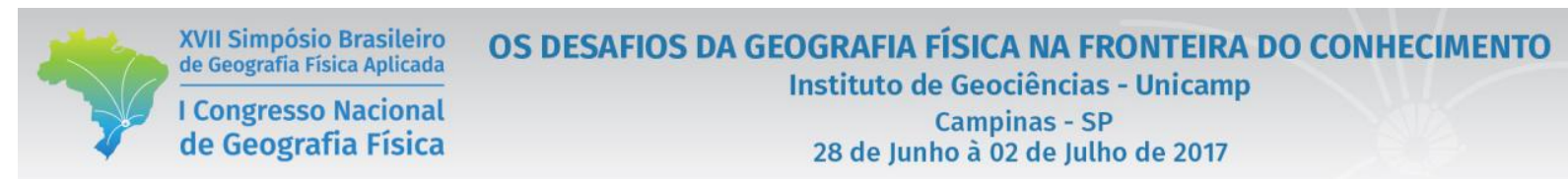

de seus elementos componentes da estrutura urbana, forma e tipologia das edificações, que lançam sombras ou canalizam os ventos (LABAKI et al, 2011, p.26).

Em relação à importância da vegetação arbórea nos espaços urbanos Amorim (2009); Mascaró (2002; 2009) e Nucci (2008) descrevem suas diversas funções enquanto um atributo responsável pelo controle do clima, da poluição, como áreas de lazer, na amenização térmica, equilíbrio da umidade do ar, que refletem diretamente na qualidade de vida dos citadinos. Em se tratando de áreas verdes enquanto parte dos espaços públicos de lazer, Nucci (2008, p.35) estende suas funções ao considerar que:

[...] propiciam um isolamento da área em relação aos transtornos da rua, o entorno, a acessibilidade, a porcentagem de área permeável, as espécies vegetais naturais e as exóticas, a densidade de vegetação, a altura da vegetação, a função social, os equipamentos de recreação, telefonia, estacionamento, bancos, sombras, tráfego, manutenção, valor estético, ecológico, serviços, iluminação, calçamento, isolamento visual, sanitários, avifauna, etc (NUCCI, 2008, p.35).

Os ambientes construídos com diferentes superfícies urbanas possuem respostas térmicas distintas influenciadas pelos materiais as constituem. Por sua vez, cada uma destas superfícies apresenta um comportamento térmico, pois segundo Leão (2008, p.11):

Os materiais utilizados nas construções urbanas têm grande capacidade de armazenar calor, aumentando a temperatura nas áreas mais urbanizadas, tanto durante o dia, quando estas superfícies estão armazenando calor, quanto no período noturno quando a energia acumulada ao longo do dia é rapidamente liberada para a atmosfera (LEÃO, 2008, p.11).

Em suma os produtos do clima urbano implicam na necessidade de adentrar a cidade, no seu interior e compreendê-la enquanto fato social "produtor de uma acentuada gama de derivações progressivas "edificando" um novo contexto topográfico pulsando na mais acentuada e complexa das dinâmicas, e refletindo, como espelho, todo o caldo cultural de uma dada sociedade" (MONTEIRO, 1990, p.9).

\section{Procedimentos metodológicos}

A seleção dos pontos fixos priorizou setores geográficos com características distintas de morfologia urbana, sítio, vegetação arbórea e padrão construtivo das edificações. Para obtenção dos dados de temperatura do ar $\left({ }^{\circ} \mathrm{C}\right)$ e umidade relativa do ar (\%) foram instalados 8 pontos fixos (Tabela I) com miniabrigos meteorológicos utilizando sensores de registro DATA Logger no período de 28 de março a 01 de maio de 2014, com registro horário às 18 h no período sazonal de outono. O ponto 9 foi representativo do espaço periurbano com dados da Estação meteorológica automática do INMET, sendo utilizado como dados de controle em relação aos 8 pontos de registro urbanos para mensuração das diferenças térmicas e higrométricas. O tratamento dos dados registrados nos pontos fixos foi feito no Surfer $^{l}$, transformando a planilha em grade com pontos equidistantes e aplicada a interpolação dos dados pelo método geoestatístico da Krigagem (SILVA, 1999, p.175).

\footnotetext{
${ }^{1}$ Surfer é marca registrada da Golden Software.
} 
A análise da temperatura da superfície através do canal termal foi outro elemento geourbano analisado a partir de imagens tomadas nos meses investigados. O sensoriamento remoto, de acordo com a American Society for Photogrammeetry and Remote Sensing (AS-PRS), consiste na medição ou aquisição de informação de alguma propriedade de um objeto ou fenômeno por meio de um dispositivo de registro que não esteja em contato físico com o objeto/fenômeno estudado. Para isso foi utilizada a imagem do satélite gratuita Landsat 8 através do site da organização United States Geological Survey (USGS) banda 10 do infravermelho termal, correspondente à órbita/ponto 220/075 do dia 04 de abril de 2014. O processamento baseou-se nas variáveis fixas e fórmulas de conversão ${ }^{2}$ de níveis de cinza em radiância e por fim em ${ }^{\circ} \mathrm{C}$.

O procedimento do transecto móvel foi realizado às $18 \mathrm{~h}$ ao pôr do sol, dia 04 de abril de 2014 em condições atmosféricas estáveis, ventos fracos e céu claro. Foi utilizado um veículo com sensor exterrno acoplado em uma haste de 1,5m de altura nos trajetos A-B (leste-noroeste) e C-D (norte-sul). Com os dados de intensidade da temperatura do ar foi elaborada a carta de isotermas através do programa Surfer.

\section{Resultados e discussões}

Em relação às caracteríticas geoambientais dos pontos selecionados verifica-se uma diversidade de padrões, por exemplo, os pontos 4 (Vila Nery) e 5 referem-se respectivamente, a um bairro residencial tradicional com dimensões das quadras idênticas as do ponto 5 (Centro - CDCC/USP) quadrangulares e arborização densa predominantemente no fundo dos lotes no ponto 4 e em praças centrais no ponto 5 . $\mathrm{O}$ ponto 1 situado no setor geográfico a norte da malha urbana apresenta vegetação arbórea e natural densa em um bosque municipal. $\mathrm{O}$ ponto 2 destaca-se pela presença de verticalização em bairro residencial e predominantemente universitário com arborização esparsa e densa nas dependências da USP/SC.

\footnotetext{
${ }^{2}$ Disponível em: $<$ http://landsathandbook.gsfc.nasa.gov/data_prod/prog_sect11_3.html>. Acesso em: 28/04/2014.
} 


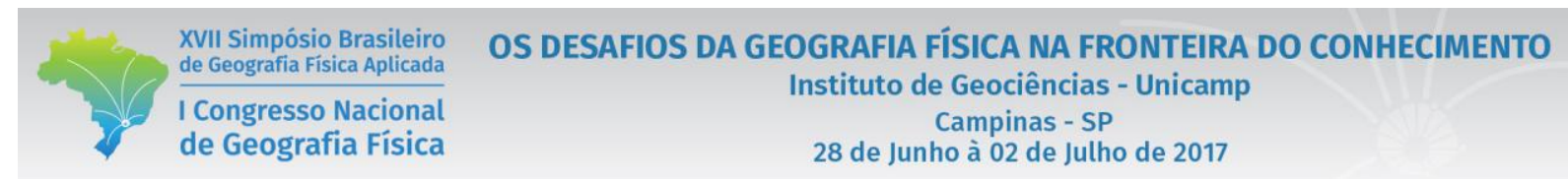

A síntese das características geourbanas e ambientais dos pontos são descritas na Tabela I a seguir:

Tabela I - Quadro síntese com as características de cada ponto fixo urbano. Imagens obtidas no Google Earth (escala aproximada do Street View). Fonte das fotos: Arquivo pessoal obtido em trabalho de campo.

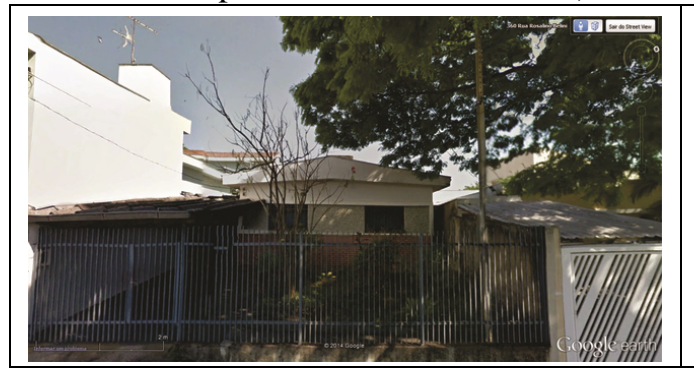

Ponto 1 - Jardim Santa Paula

- 819 metros de altitude; - Declividade entre 10 a $15 \%$ com vertente voltada para o leste;

- Localizado na região norte/noroeste da malha urbana;

- Alta densidade de construção com cobertura das edificações predominante de telha cerâmica;

- Vegetação arbórea e natural e Bosque.

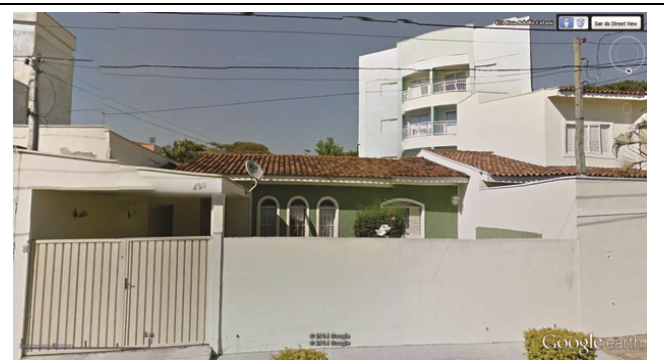

\section{Ponto 2 - Jardim Macarengo}

- 855 metros de altitude; - Declividade entre 05 a $10 \%$ com orientação da vertente voltada para o norte;

- Localizado na região centro-norte da malha urbana;

- Destinação do bairro residencial familiar e estudantil com alta densidade de construção;

- Verticalização de 2 a 15 pavimentos;

- Vegetação arbórea esparsa.

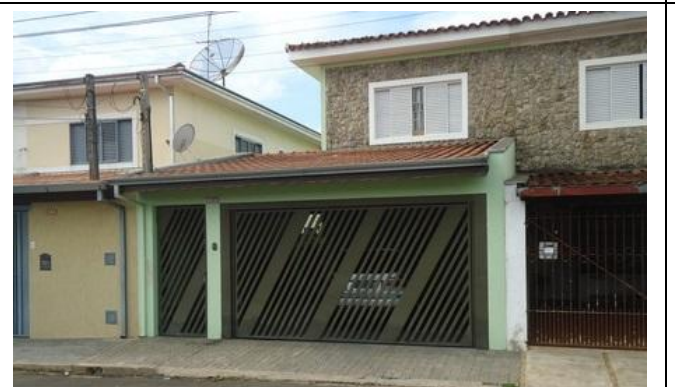

\section{Ponto 3 - Jardim São João Batista}

- 873 metros de altitude; - Declividade entre 0 a $5 \%$ com orientação da vertente voltada para o norte;

- Malha viária com morfologia ortogonal retangular, densamente edificado;

- Presença de canteiros sem edificação;

- Áreas de lazer (Jd. Jockey Club de São Carlos e UFSCar) a nordeste da malha viária;

- Arborização esparsa e densa (a norte).

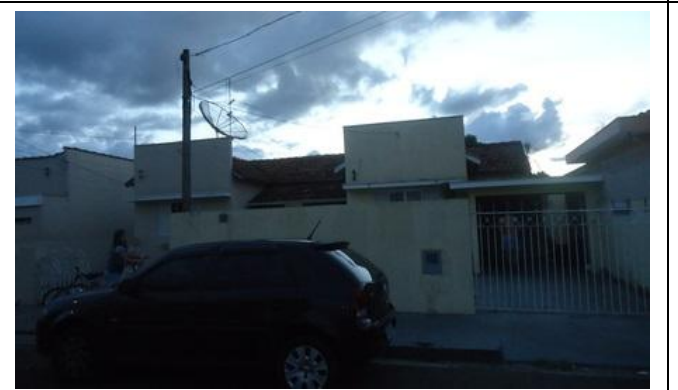

\section{Ponto 4 - Vila Nery}

- 883 metros de altitude; - Declividade entre 0 a $5 \%$ com orientação da vertente voltada a sudoeste;

- Localizado no setor geográfico leste da malha urbana;

- Bairro residencial tradicional, densamente ocupado, com quadras quadrangulares;

- O bairro apresenta vegetação densa disposta, principalmente, no fundo dos lotes.

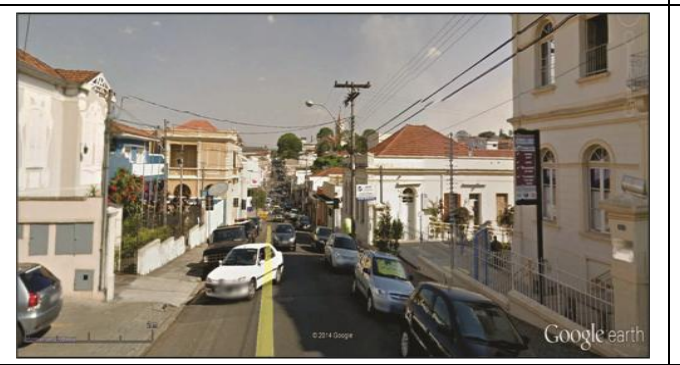

\section{Ponto 5 - Centro - CDCC/USP}

- 806 metros de altitude em fundo de vale; - Declividade do terreno entre 0 a $5 \%$ no centro e, de 20 a $25 \%$ a norte;

- Densamente construído e lotes grandes;

- Uso do solo comercial e de serviços;

- Coberturas de fibrocimento e metálicas;

- Presença de Verticalização e alta impermeabilização;

- Arborização densa em praças centrais. 
XVII Simpósio Brasileiro de Geografia Física Aplicada

I Congresso Nacional de Geografia Física
OS DESAFIOS DA GEOGRAFIA FÍSICA NA FRONTEIRA DO CONHECIMENTO

Instituto de Geociências - Unicamp

Campinas - SP

28 de Junho à 02 de Julho de 2017

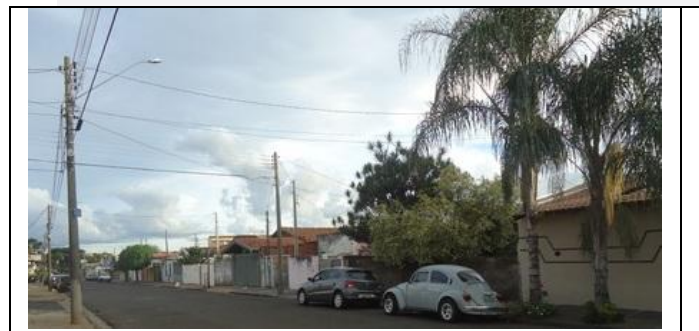

\section{Ponto 6 - Vila Bella Vista}

- 837 metros de altitude; - Declividade de 05 a 10\%;

- Orientação das vertentes predominantemente a sudoeste;

- Edificações com menor padrão construtivo;

- Alta densidade de construção e morfologia com quadras retangulares e cobertura das edificações mista;

- Arborização esparsa a ausente.

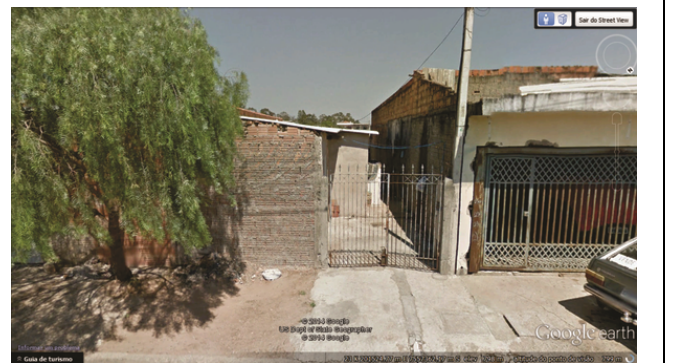

\section{Ponto 7 - Loteamento Cidade Aracy}

- 792 metros de altitude; - Declividade do terreno de 05 a 10\%, com orientação das vertentes voltadas para sul;

- Morfologia do bairro visivelmente distinta com elevado adensamento construtivo e lotes com dimensão pequena e alta densidade populacional;

- Cobertura das edificações predominante de fibrocimento;

- Proximidade de APP, arborização ausente nas vias.

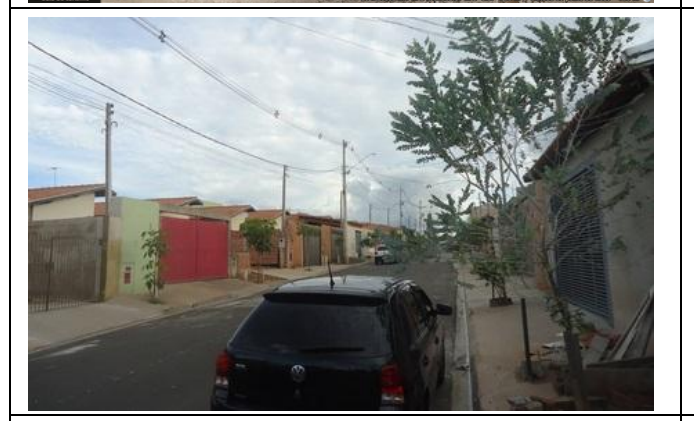

Ponto 8 - Conj. Hab. Novo Mundo

- 835 metros de altitude; - Declividade de 0 a $5 \%$ com vertente orientada a noroeste;

- Padrão construtivo adensado com lotes pequenos e próximos com cobertura das edificações de telha cerâmica;

- Impermeabilização significativa do solo;

- Quadras retangulares pequenas com morfologia urbana ortogonal;

- Arborização ausente e quando presente de pequeno porte.

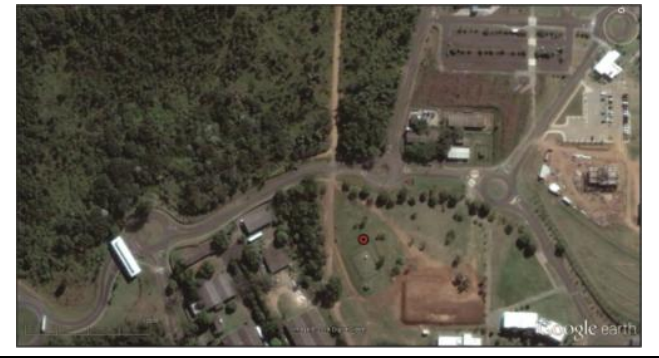

Ponto 9 - Periurbano / Estação Meteorológica Automática INMET UFSCar

- 860 metros de altitude; - Declividade de 0 a $5 \%$ com vertente orientada a oeste;

- Localizado no setor geográfico nordeste do perímetro urbano nas dependências da UFSCar;

- Baixa densidade de construção e distante $2 \mathrm{~km}$ da área urbana;

- Arborização densa de mata nativa e proximidade de cursos d'água.

O ponto 3 apresenta alta impermeabilização do solo com arborização esparsa a densa (norte na UFSCar e Embrapa Pecuária Sudeste). O ponto 6 apresenta morfologia urbana distinta com edificações de menor padrão construtivo com quadras retangulares e cobertura de telhas mistas (cerâmica e fibrocimento), arborização esparsa a ausente. Por fim, os pontos 7 e 8 referem-se, respectivamente a um conjunto habitacional popular com lotes pequenos, alta densidade construtiva e arborização ausente e, o ponto 8 é um loteamento popular localizado no extremo sul da malha viária com lotes e quadras pequenas.

O gradiente de temperatura da superfície dos alvos em 04 de abril de 2014 foi de $20^{\circ} \mathrm{C}$ a $31^{\circ} \mathrm{C}$ no período sazonal de outono (Figura 2). A tomada da imagem compreendeu a ocorrência de precipitação em dias anteriores o que aumentou a disponibilidade de água no solo. 

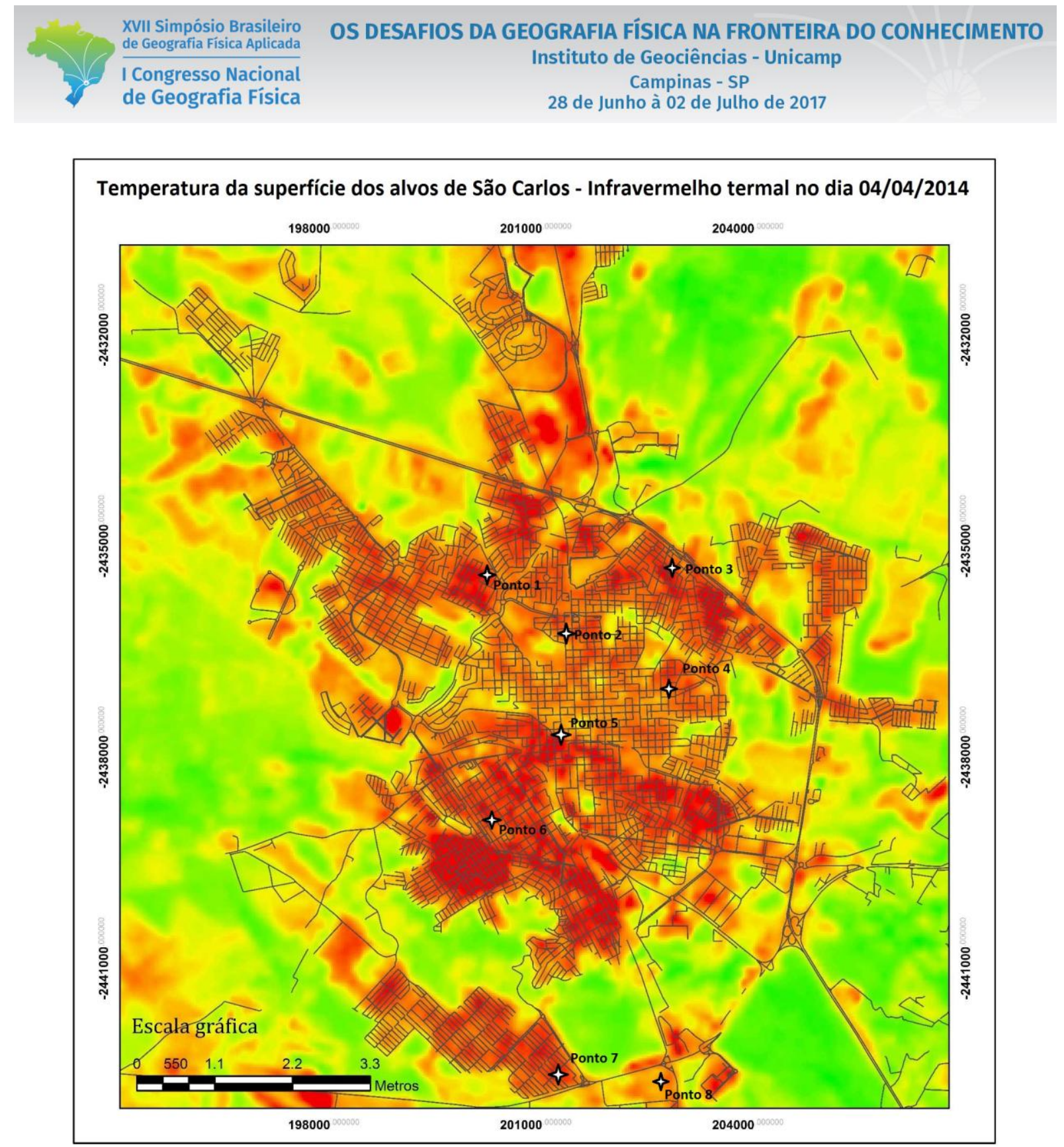

Figura 2 - Carta de temperatura da superfície de São Carlos/SP, canal infravermelho termal do satélite Landsat 8, 04/04/2014. Fonte: <http://landsat.usgs.gov/Landsat8_Using_Product.php>. Org.: RAMPAZZO, C. R. (2014)

No âmbito da malha viária destaca-se a influência da vegetação arbórea densa e dos cursos d'água na diminuição da temperatura dos alvos, com variação de temperatura significativamente inferior entre $23^{\circ} \mathrm{C}$ e $27^{\circ} \mathrm{C}$. No setor geográfico a extremo norte evidenciam-se as áreas de experimento da EMBRAPA Pecuária Sudeste e dependências da UFSCar com temperatura variando de $20^{\circ} \mathrm{C}$ a $25^{\circ} \mathrm{C}$.

Em contraposição a leste e noroeste da imagem notam-se alvos temperaturas de $31^{\circ} \mathrm{C}$ associados à resposta termal de solo exposto. Destacam-se alguns bairros dos setores geográficos da cidade, por exemplo, a Vila Bela Vista, Vila Boa Vista 1, Vila Boa Vista 2, Jardim Beatriz e Jardim Cruzeiro do Sul 


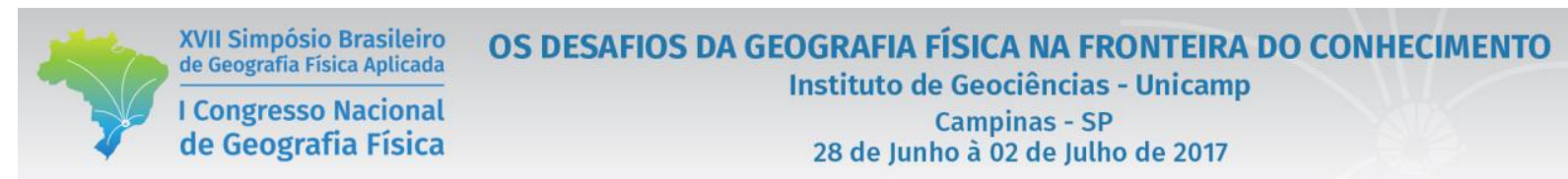

na zona sul da malha urbana no reverso da cuesta (em média a 860 metros de altitude). E também o loteamento de interesse social Cidade Aracy no extremo sul da malha urbana abaixo do reverso da cuesta (sítio urbano com altitude média de 750 metros). Estes setores geográficos apresentaram temperaturas mais elevadas entre $27^{\circ} \mathrm{C}$ e $30^{\circ} \mathrm{C}$. Além destes, bairros entre o Córrego do Tijuco e Avenida Washington Luiz no setor geográfico a norte da cidade também apresentaram temperatura elevada entre $26^{\circ} \mathrm{C}$ a $28^{\circ} \mathrm{C}$. Já os demais locais, notadamente o centro antigo apresentou temperaturas inferiores, entre $24^{\circ} \mathrm{C}$ e $26^{\circ} \mathrm{C}$.

Relacionando a variação de temperatura dos alvos em relação aos registros de temperatura do ar nos pontos fixos, nota-se que as diferenças de temperatura entre os pontos (Figura 3) foram de $5,5^{\circ} \mathrm{C} \mathrm{a}-3,5^{\circ} \mathrm{C}$.

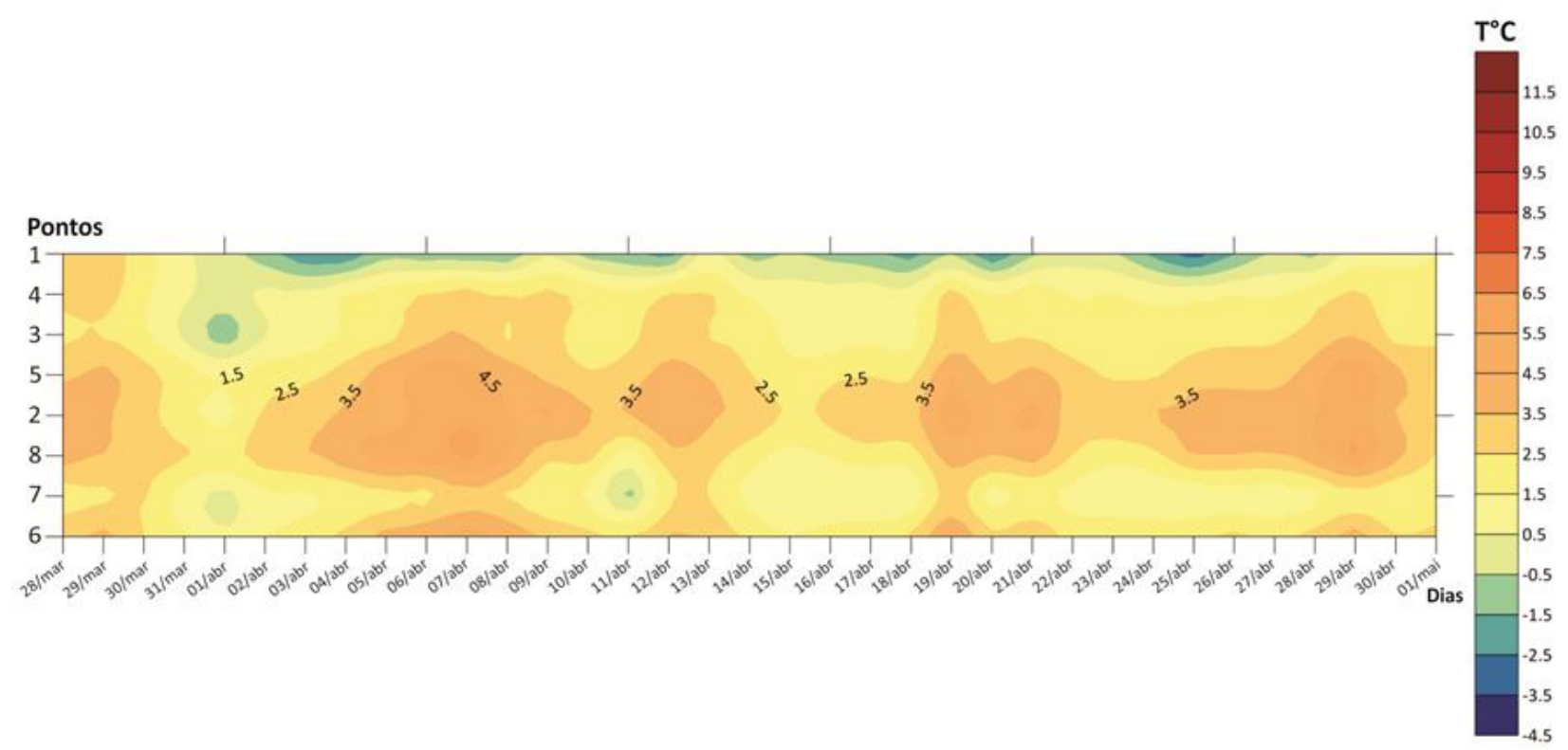

Figura 3 - Variação espacial e temporal das diferenças de temperatura do ar obtidas por pontos fixos às $18 \mathrm{~h}$

É possível identificar a influência das particularidades espaciais, já descritas na Tabela I, na configuração destas diferenças térmicas, por exemplo, no Jd. Macarengo (ponto 2), Centro CDCC/USP (ponto 5), Vila Bella vista (ponto 6) e Conj. Habitacional Novo Mundo (ponto 8) que apresentaram um padrão de diferenças térmicas com a formação de "ilhas de calor" com intensidades de $3,5^{\circ} \mathrm{C}$ a $5,5^{\circ} \mathrm{C}$. A umidade relativa do ar (Figura 4) nestes pontos foi inversamente proporcional com gradientes percentuais de $-6 \%$ a -14\%. Além destes, o ponto 7 referente ao loteamento Cidade Aracy com elevado adensamento construtivo em lotes pequenos (cobertura das edificações predominante de fibrocimento) e arborização ausente nas vias também apresentou umidade relativa de $-6 \%$ a $-10 \%$. Estes pontos se diferenciam notadamente em relação aos pontos 1, 3, 4 e 7. O ponto 1, por exemplo, durante o período de 01 a 29 de abril apresentou diferenças térmicas negativas de pelo menos $-2,5^{\circ} \mathrm{C}$ e, neste caso, destaca-se a influência da proximidade de vegetação densa em um bosque municipal. O ponto 4 localizado no bairro tradicional 


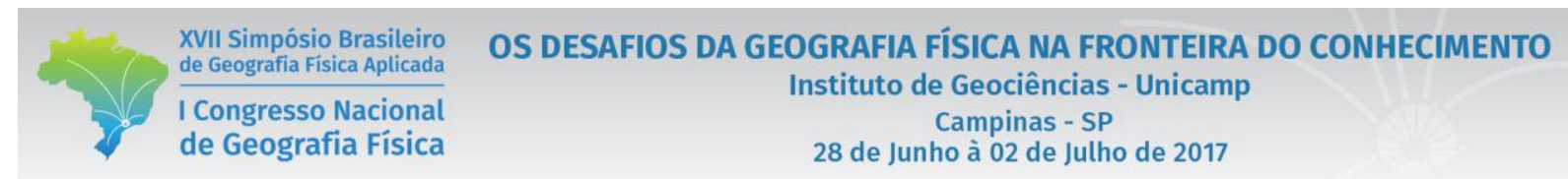

de São Carlos apresentou durante todo o período diferenças térmicas que variaram de $0,5^{\circ} \mathrm{C}$ a $1,5^{\circ} \mathrm{C}$ e em situações episódicas de 28 a 29 de março apresentou temperaturas de $3,5^{\circ} \mathrm{C}$ e umidade relativa de $-8 \%$.

Já os pontos 1, 3 e 4 apresentaram em alguns períodos umidade relativa do ar elevada em relação ao ponto fixo periurbano, variando de $6 \%$ a 10\%. Estas condições ocorreram em períodos específicos do dia 31 de março a 04 de abril e de 16 a 19 de abril sob atuação de sistemas instáveis de alta pressão do Atlântico $\mathrm{Sul}^{3}$ como a FPA (Frente Polar Atlântica) e FPAE (Frente Polar Atlântica Estacionária), com nebulosidade e ocorrência de precipitação de $30 \mathrm{~mm}$ no dia 02 de abril e pouco mais de $5 \mathrm{~mm}$ no dia 16 de abril.

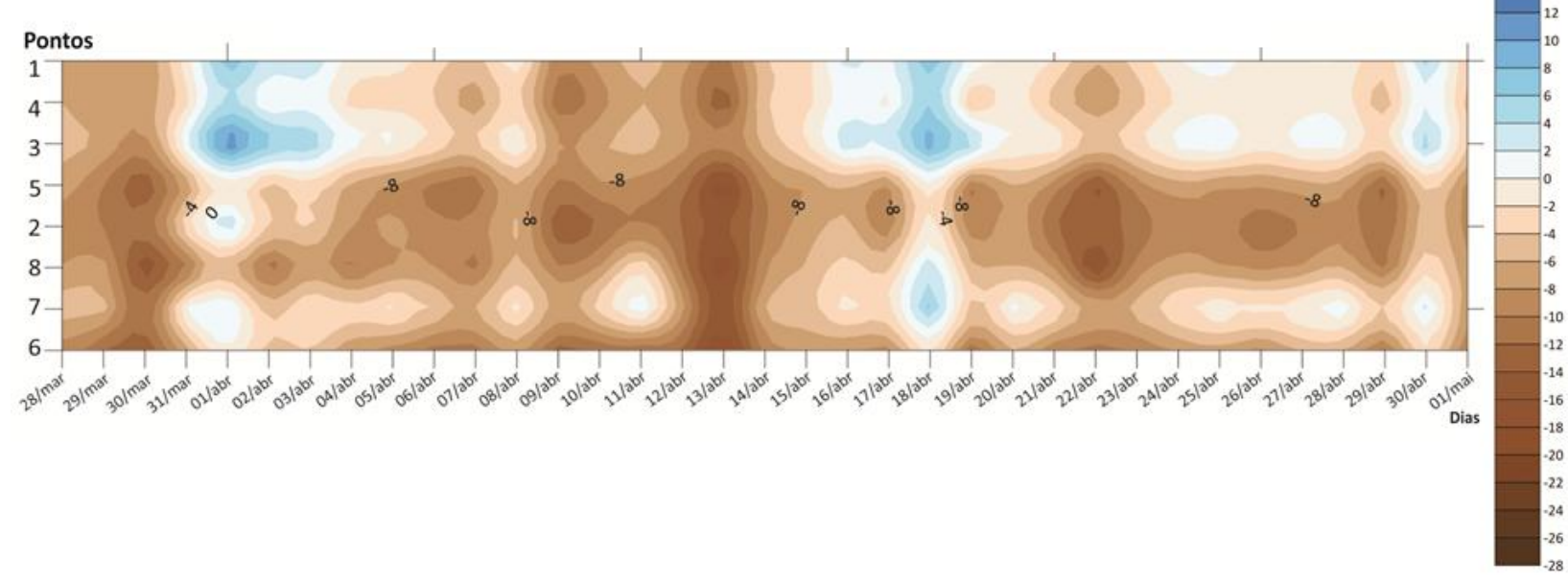

Figura 4 - Variação espacial e temporal das diferenças de umidade relativa do ar obtidas por pontos fixos às $18 \mathrm{~h}$

Neste mesmo horário às $18 \mathrm{~h}$ foram realizadas as medições móveis nos transectos A-B e C-D (Figura 5) e verfica-se uma configuração de bolsões mais aquecidos da temperatura do ar que corresponderam aos verificados na carta de temperatura de superfície dos alvos, por exemplo, na zona sul e sudoeste da malha urbana nos bairros Vila Bela Vista, Vila Boa Vista 1, Vila Boa Vista 2, Jardim Beatriz e Jardim Cruzeiro do Sul. A temperatura do ar nestes bolsões variou de $26^{\circ} \mathrm{C}$ a $27,5^{\circ} \mathrm{C}$. No setor a norte e noroeste da malha viária verifica-se a configuração de outro bolsão mais aquecido com intensidade de $25,5^{\circ} \mathrm{C}$. Em contrapartida, em vários trechos do percurso A-B configuraram-se bolsões de ar menos aquecidos relacionados principalmente a presença de vegetação arbórea densa e cursos d'água.

\footnotetext{
${ }^{3}$ Análise rítmica realizada com o uso das cartas sinóticas de superfície da Marinha do Brasil, disponíveis em: $<$ http://www.mar.mil.br/dhn/chm/meteo/prev/cartas/cartas.htm>. Acesso em: 20 de julho de 2014. E imagens do satélite GOES, disponíveis em: <http://satelite.cptec.inpe.br/acervo/goes.formulario.logic $>$. Acesso em: 20 de julho de 2014.
} 


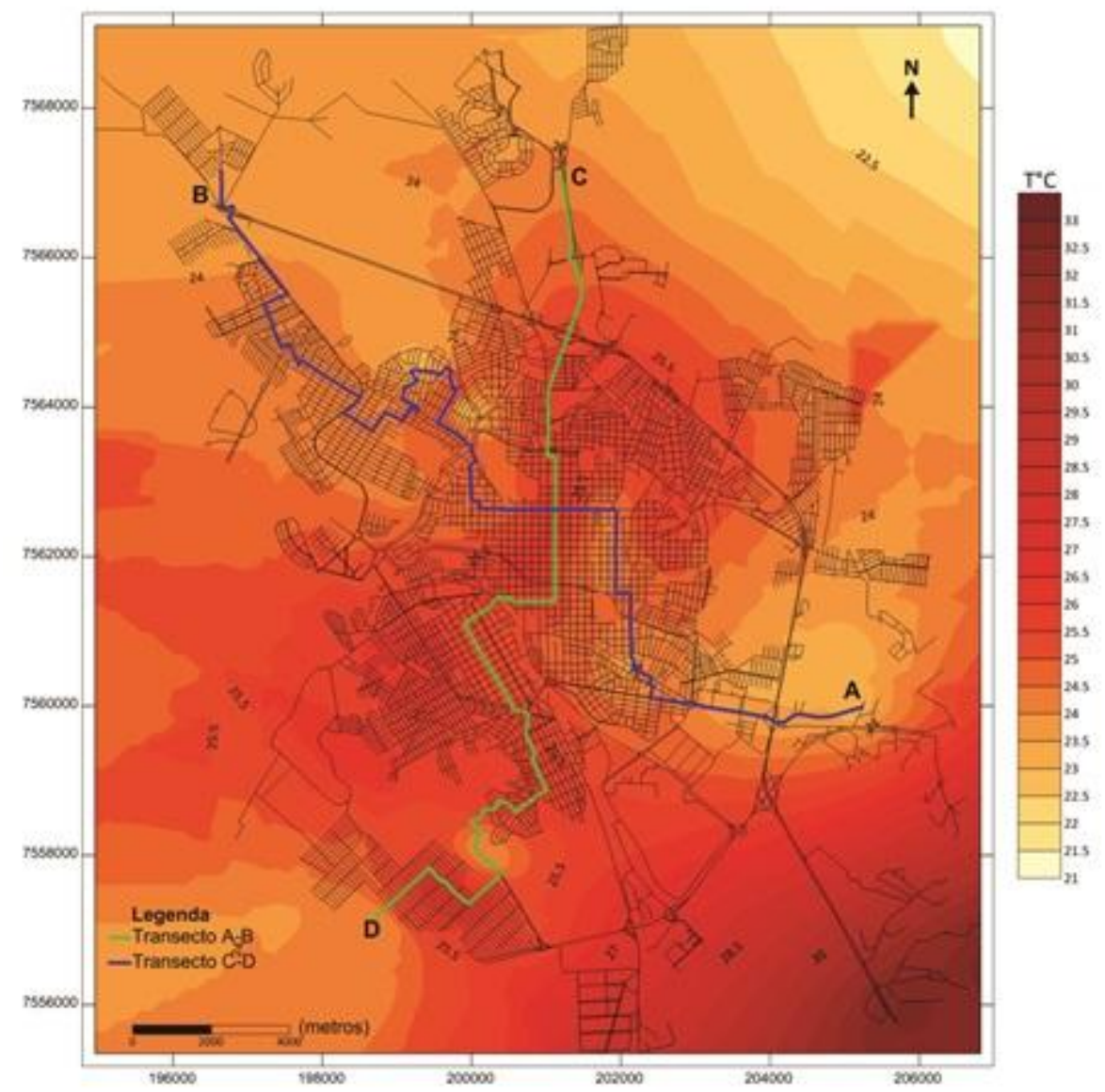

Figura 5 - Diferenças térmicas obtidas por transecto móvel no dia 04 de abril de 2014 às $18 \mathrm{~h}$

\section{Considerações finais}

Nesse estudo, a análise do clima urbano da cidade de São Carlos/SP permitiu identificar diferenças termohigrométricas com intensidade de até $5,5^{\circ} \mathrm{C}$ em diferentes condições de uso e ocupação da superfície da terra que refletem a influência direta da dinâmica desigual e contraditória de produção dos espaços.

A associação dos três procedimentos - medição em pontos fixos, trajetos móveis e sensoriamento remoto (infravermelho termal) - auxiliou no detalhamento das características do ambiente urbano e identificação dos setores geográficos mais aquecidos. Os fatores associados à geração das ilhas de calor de superfície e bolsões de ar pelas isotermas referiram-se às características de densidade e padrão construtivo, morfologia urbana, presença ou ausência de fragmentos de vegetação arbórea e solos expostos. A análise dos pontos fixos permitiu a interrelação direta entre as características geoambientais e a inércia térmica dos materiais a partir do aumento da temperatura do ar, bem como as variações das isoígras (umidade relativa do ar \%). 
Desta forma, sabe-se que a contribuição dos estudos de clima urbano vão além do planejamento urbano, pois fornecem informações para a compreensão dos fatores que tornam a atmosfera urbana diferente da periurbana e/ou rural, sobretudo no que diz respeito às anomalias térmicas e assim, auxiliam no planejamento urbano e gestão das cidades no atual cenário de emergência da problemática ambiental.

\section{Bibliografia}

AMORIM, M.C.C.T. O clima urbano de Presidente Prudente/SP. São Paulo, 2000. 378p. Tese (Doutorado em Geografia) - Faculdade de Filosofia Letras e Ciências Humanas - USP.

AMORIM, M. C. C. T.; DUBREUIL, V.; QUENOL, H.; SANT'ANNA NETO, J. L. Características das ilhas de calor em cidades de porte médio: exemplos de Presidente Prudente (Brasil) e Rennes (França). Confins (Paris), v.7, p.1-16, 2009. Disponível em: 〈http://confins.revues.org/index6070.html〉. Acesso em 14 de janeiro de 2014.

AMORIM, M. C. C. T. Os climas urbanos em cidades localizadas na raia divisória São Paulo - Paraná - Mato Grosso do Sul. In: A Raia Divisória São Paulo - Paraná - Mato Grosso do Sul (cenas e cenários). Ed.Outras Expressões, 1.ed. São Paulo, 2011. p.133-165.

BARBIRATO, G. M.; SOUZA, L. C. L. de.; TORRES, S. C. Clima e cidade: a abordagem climática como subsídio para estudos urbanos. Maceió: EDUFAL, 2007.164p.

DEÁK, Csaba; SCHIFFER, Sueli R. (Orgs). O processo de urbanização no Brasil. São Paulo: Editora Fupam/Edusp, 1999.

FIALHO, Edson S. Estudos climáticos em sítios urbanos e rurais. In: SILVA, C. A.; FIALHO, Edson. S. (org). Concepções e Ensaios da Climatologia Geográfica. E-book, 2012, p. 83-114.

LABAKI, Lucila C.; SANTOS, Rozely F. dos S.; BUENO-BARTHOLOMEI, Carolina L.; ABREU, Loyde V. de A. Vegetação e conforto térmico em espaços urbanos abertos. Fórum Patrimônio. Mudanças climáticas e o impacto das cidades. Belo Horizonte, v. 4, n. 1, p. 23-42, 2011.

LEÃO, M. S. Diagnóstico climático e estudos das variações termo-higrométricas do município de Sete Lagoas MG. 150f. Dissertação de mestrado. Instituto de Geociências. Universidade Federal de Minas Gerais, 2008.

LOMBARDO, M. A. Ilha de Calor nas Metrópoles: O Exemplo de São Paulo. São Paulo: Hucitec, 1985. 244p.

MASCARÓ, Lúcia; MASCARÓ. Juan J. Vegetação Urbana. Porto Alegre: Finep. 1ªed. 2002.

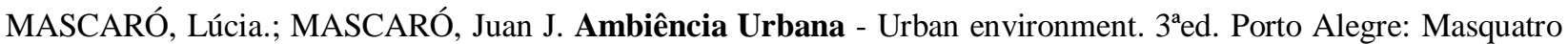
Editora, Edição Bilíngue, 2009.

MONTEIRO. C. A. F.; MENDONÇA, F. (Org.). Clima Urbano. 1.ed., São Paulo: Contexto, 2009. 192p.

NUCCI, João Carlos. Qualidade Ambiental e Adensamento Urbano. Um estudo de Ecologia e Planejamento da Paisagem aplicado ao distrito de Santa Cecília (MSP). $2^{\mathrm{a}}$ edição. Curitiba: O autor, 2008. 150p.

SANT'ANNA NETO, João Lima. O clima urbano como construção social: da vulnerabilidade polissêmica das cidades enfermas ao sofisma utópico das cidades saudáveis. Revista Brasileira de Climatologia. Ano 7 - Vol. 8 JAN/JUN/2011.

SILVA, A. de B. Sistemas de Informações Geo-referenciadas: Conceitos e fundamentos. Campinas: Editora da Unicamp, 1999.

A agência de fomento da Fapesp (Fundação de Amparo à Pesquisa do Estado de São Paulo) pelo financiamento da pesquisa de Dissertação de Mestrado e atividades de campo no Processo 2013/04417-3. 